\title{
NATURALISM AND MORAL REALISM ${ }^{\dagger}$ \\ MICHAEL C. REA \\ UNIVERSITY OF NOTRE DAME
}

My goal in this paper is to show that naturalists cannot reasonably endorse moral realism. In defending this conclusion, I mean to contribute to a broader anti-naturalistic project. Elsewhere (Rea 1998, 2002), I have argued that naturalists must give up realism about material objects, materialism, and perhaps even realism about other minds. Materialism aside, I take realism about material objects and realism about other minds to be important parts of our commonsense metaphysics. Likewise, I take moral realism to be an important part of commonsense morality. Insofar as it conflicts with these important parts of our commonsense view of the world, naturalism is unattractive. Of course, one might doubt that unattractiveness counts as evidence against a philosophical position; but, as I'll explain below, I think that naturalism is not a philosophical position, but a research program. Moreover, I have argued elsewhere (Rea 2002) that naturalism, like any other research program, must be adopted or rejected solely on the basis of its pragmatic appeal (or lack thereof). It is for this reason that highlighting unattractive features of naturalism is an important way of attacking it.

Moral realism is the view that there are objective moral facts. ${ }^{1}$ There are objective moral facts only if the following two conditions are met: (i) there are moral properties-e.g., properties like being a right action, being a wrong action, being praiseworthy, being depraved, and so onat least some of which are exemplified by actual objects or events, and (ii) the exemplification of

\footnotetext{
$\dagger$ I am grateful to Michael Bergmann, Jeff Brower, David Haslett, Trenton Merricks, Christian Miller, Mark Murphy, and Alvin Plantinga for generous and very helpful comments on earlier versions of this paper.
} 
a moral property $p$ does not entail that anyone has beliefs about what exemplifies $p$, about whether $p$ is exemplified at all, or about the conditions under which $p$ is exemplified. Condition (ii) is meant to express part, but only part, of what many philosophers aim to express by phrases like 'moral properties are not mind-dependent' or 'moral facts are not theory-dependent'. ${ }^{2}$

Some naturalists already accept the conclusion that I want to defend here, but many continue to resist it. For reasons that will become clear below, those who resist have typically done so by arguing for one of the following claims:

(C1) Regardless of whether they are reducible to non-moral properties, objective moral properties play an indispensable role in the best causal explanations of at least some natural phenomena (e.g., moral beliefs and judgments, or morally significant behavior).

(C2) Moral properties are reducible to non-moral properties which, in turn, play an indispensable role in the best causal explanations of various natural phenomena.

Part of what I aim to show is that, contrary to widespread opinion, neither of these claims offers any promising line of resistance against the conclusion I'll be defending.

My argument will come in two parts. The first part aims to show that any plausible and naturalistically acceptable argument in favor of belief in objective moral properties will appeal in part to simplicity considerations (broadly construed) - and this regardless of whether moral properties are reducible to non-moral properties. By 'simplicity considerations (broadly construed)' I mean just those considerations that reflect our preference, ceteris paribus, for theories that are elegant, ontologically economical, mathematically simple, and consistent with

\footnotetext{
${ }^{1}$ I take it that, even if the present understanding of moral realism is controversial, it is not idiosyncratic. (Cf. Boyd 1988, Brink 1989, Railton 1986, and Smith 1994.)
} 
our considered judgments, theoretical commitments, and other entrenched background presuppositions. ${ }^{3}$ (Such considerations are often referred to as 'pragmatic' considerations; but I avoid that label because I do not want to presuppose that they are merely pragmatic and thus not indicative of truth.) Henceforth, I will speak of an appeal to such considerations just as an "appeal to simplicity".

The second part argues for the conclusion that appeals to simplicity justify belief in moral properties only if either those properties are not objective or something like theism is true. Thus, if my argument is sound, naturalists can reasonably accept moral realism only if they are prepared to accept something like theism. But, as will become clear, naturalists can reasonably accept theism or something like it only if belief in some such doctrine is justified by the methods of science. For present purposes, I'll assume (what I think virtually every naturalist will grant) that belief in theism and relevantly similar doctrines is not justified by the methods of science. Thus, I will conclude that naturalists cannot reasonably accept moral realism. Before presenting the details of the argument, however, I'll first say a few words about the nature of naturalism.

\section{Naturalism}

As I understand it, naturalism is not a view, or a philosophical thesis, but a research program. A research program is a set of methodological dispositions-dispositions to trust particular cognitive faculties as sources of evidence and to treat particular kinds of experiences and arguments as evidence. Naturalism, so I say, is a research program that treats the methods of science, and those methods alone, as basic sources of evidence (where a putative source of

\footnotetext{
2 Thus, conditions (i) and (ii) provide necessary, but not sufficient, conditions for objectivity. To get in the neighborhood of a sufficient condition, we would have to add that the exemplification of a moral property $p$ is in some relevant sense independent of actual human desires and attitudes.
} 
evidence is treated as basic just in case it is trusted in the absence of evidence in favor of its reliability).

In characterizing naturalism this way, I put myself at odds with many philosophersnaturalists and non-naturalists alike. But the philosophers with whom I am at odds are not at all unified in their views about what naturalism is. Some say that naturalism is primarily a metaphysical view (for example, the view that the universe is a closed causal system). ${ }^{4}$ Others say that it is primarily an epistemological view (for example, the view that scientific inquiry is the only avenue to knowledge). ${ }^{5}$ Still others say that it is primarily a view about philosophical methodology (for example, the view that philosophers ought to abandon traditional problems about skepticism and ontology and pursue their various projects in a way continuous with the methods of science). ${ }^{6}$ Most naturalists would affirm Wilfrid Sellars's slogan that "science is the measure of all things: of what is that it is and of what is not that it is not" (Sellars 1963: 173); and many, no doubt, would say that this slogan captures the heart and soul of naturalism. But apart from that, there is little agreement about what, precisely, naturalism amounts to.

It is tempting, in light of the proliferation of different and conflicting formulations of naturalism, to say that naturalism comes in different varieties, each expressible by a different philosophical thesis. Those who give in to this temptation typically list three varietiesmetaphysical, epistemological, and methodological—though once in a while other varieties are identified. ${ }^{7}$ Different philosophers are then labeled not simply as naturalists but as metaphysical,

\footnotetext{
${ }^{3}$ For further, more detailed discussion of simplicity as I am understanding it here, see Koons 2000, Swinburne 2001 (Ch. 4), and Weinberg 1994 (Ch. 6).

${ }^{4}$ See, e.g., Armstrong 1980: 35 and Danto 1967: 448.

${ }^{5}$ See, e.g., Quine 1995: 257 and Devitt 1998: 45.

${ }^{6}$ See, e.g., Leiter 1998: 81.

7 Indeed, giving into this temptation is now the standard way of characterizing naturalism. See, e.g., Schmitt 1995, Hampton 1998: 19 - 21, and Katz 1998: xii.
} 
epistemological, or methodological naturalists, depending on which of the relevant theses they seem to endorse.

But this is not the only way of accounting for the diversity of formulations of naturalism. Another possibility is that there is indeed only one version of naturalism, but many mischaracterizations of it. Given the current state of the literature, to embrace this possibility is to say that many naturalists have mischaracterized their own naturalism. Saying this might seem uncharitable. It might also seem implausible. Nevertheless, I think that there are very good reasons for doing so.

Despite all the disagreement about how to formulate naturalism, almost every naturalist agrees that naturalism somehow involves deep respect for the methods of science above all other forms of inquiry. To the extent that one fails to manifest a disposition to follow science wherever it leads, one fails to count as a naturalist. But if we take this idea seriously, then we are led fairly directly to the conclusion that naturalism couldn't be a substantive philosophical thesis. For naturalists will agree that any substantive thesis that we might plausibly identify with naturalism is itself at the mercy of science. That is, any such thesis must be justified by the methods of science, if at all; and any such thesis can, at least in principle, be overthrown by scientific investigation. But no one seems to think that naturalism itself would be refuted if science were to produce evidence against some favored thesis of (e.g.) metaphysics, epistemology, methodology, or semantics. Again, the heart of naturalism is to follow science wherever it leads; but, clearly enough, one cannot be a naturalist and be disposed to follow science wherever it leads if naturalism itself is inextricably tied to some thesis that science might overthrow. To suppose that naturalism involves dogmatic adherence to a substantive philosophical thesis is, therefore, either to suppose that naturalists one and all have fallen into a rather elementary and uninteresting sort 
of incoherence or to suppose that, appearances to the contrary, naturalists are not really unified by a disposition to follow science wherever it leads. But neither of these alternatives seems plausible. Thus, in my view, it is much better (and, ultimately, more charitable) to say that naturalism is not a thesis, but something else.

I suppose there are many other things naturalism could be: an attitude, a value, a preference, etc. However, in light of what the most prominent $20^{\text {th }}$ century naturalists have said about it, my own view is that naturalism is best characterized as a research program. Taking it this way fits very nicely with the characterizations (slogans aside) offered by its most prominent spokesmen in the $20^{\text {th }}$ Century-John Dewey and W. V. Quine. Moreover, it faithfully captures what is common to virtually all of those who call themselves naturalists without falling prey to the problem (briefly described above) that besets any attempt to express naturalism as a thesis. As I see it, then, what unifies naturalists is not adherence to a philosophical position, but rather a disposition to conduct inquiry in a certain way-a way dominated by the methods of science. ${ }^{8}$

What are the methods of science? Notoriously, it is hard to say exactly what they are. But we can say very roughly that the methods of science are, at present anyway, those methods (including canons of good argument, criteria for theory choice, and the like) that are regularly employed and respected in contemporary university science departments (e.g., departments of biology, chemistry, geology, physics, etc.). Reliance on memory and testimony is surely included among these methods, as are judgments about apparent mathematical, logical, and conceptual truths. Ruled out, on the other hand, are evidential appeals to ungrounded hunches, rational intuitions (conscious episodes in which a proposition seems to be necessarily true), putative

\footnotetext{
${ }^{8}$ For a fuller defense of these claims, a fuller explanation of the term 'research program', a more thorough argument for the conclusion that naturalism is not a thesis, and for references to Dewey, Quine, and other prominent naturalists, see Part 1 of Rea 2002.
} 
divine revelations or religious experiences, manifestly unreliable sources of testimony, and the like. ${ }^{9}$ Again, this characterization is rough; but it will do well enough for present purposes.

\section{Science and Morality}

In light of the characterization of naturalism just given, it should be clear that a naturalistically respectable argument for any conclusion will be one that appeals only to premises that can be known by way of the methods of science. In this section, I will argue that any naturalistically respectable argument for belief in objective moral properties will have to appeal to simplicity.

I'll take as my point of departure Gilbert Harman's well-known argument for the general conclusion that moral realism is untenable. In short, Harman rejects moral realism on the grounds that objective moral facts have no role to play in our best causal explanations of natural phenomena. In response to his argument, those interested in defending both naturalism and moral realism have typically defended either $\mathrm{C} 1$ or $\mathrm{C} 2$ :

(C1) Regardless of whether they are reducible to non-moral properties, objective moral properties play an indispensable role in the best causal explanations of at least some natural phenomena (e.g., moral beliefs and judgments, or morally significant behavior).

(C2) Moral properties are reducible to non-moral properties which, in turn, play an indispens able role in the best causal explanations of various natural phenomena.

\footnotetext{
${ }^{9}$ But here we must add a caveat. Though it is surely right to say that rational intuition isn't generally treated as a source of evidence in science, there might be a case to be made for the conclusion that it is treated as a source of evidence in the ill-defined domain of mathematical, logical and conceptual truths. (See Rea 2002: 67, 199 - 210 for further discussion.) But even if this is right, it does not affect the present discussion; for moral truths clearly aren't mathematical or logical truths, and the phenomenon of widespread intractable disagreement is just one among several convincing pieces of evidence that they aren't sufficiently similar to paradigm cases of conceptual truths (e.g., 'All bachelors are male') to be treated as such.
} 
Indeed, as I'll make clear below, there seems to be no naturalistically respectable way of resisting Harman's argument apart from defending $\mathrm{C} 1$ or $\mathrm{C} 2$. But I'll also argue that, if this is right, then even if $\mathrm{C} 1$ or $\mathrm{C} 2$ can be successfully defended, any naturalistic argument for belief in objective moral properties will have to make some appeal to simplicity.

\subsection{Harman's Argument}

In the opening chapters of The Nature of Morality, Gilbert Harman argues that ethics is problematic because it appears that "there can be no explanatory chain between moral principles and particular observings in the way that there can be such a chain between scientific principles and particular observings." (1977: 9) The "particular observings" for which moral facts are candidate explanations are just moral observations. For example, Harman points out that if we see some young hoodlums pour gasoline on a cat and ignite it, we do not need to conclude that their behavior is wrong; we can see that it is an instance of wrong behavior just as clearly as we can see that it is an instance of cat-burning behavior. (1977: 4) But, he argues, moral facts have no role to play in explaining this sort of observation. More exactly: they have no role to play in the best causal explanation of this sort of observation (or of anything else). As he makes clear elsewhere (Harman 1984: 33 - 4; Harman 1986: 61 - 4) the point isn't that moral facts are never invoked in an explanatory way. The point, rather, is that the fact that the behavior of the catburning hoodlums is wrong, the fact that the hoodlums are depraved, and other such moral facts seem not to figure in any causal explanations of anything. Thus, Harman can grant that it makes perfect sense to say (e.g.) that we are repulsed by the behavior of the cat-burning hoodlums because the behavior is wrong, and that the children are behaving in that way because they are depraved. The point is just that the wrongness of their behavior does not cause our observation 
that the behavior is wrong, nor does it cause our repulsion at that behavior; and the depravity of their character does not cause the hoodlums to burn the cat. ${ }^{10}$ All of these events have perfectly natural, non-moral causes, and it is those causes, rather than any alleged moral facts, that seem to figure in the best (causal) explanations of their effects. But if that's right, Harman thinks, then, absent a reduction of moral facts to non-moral ones, we have no scientific reason—and hence, on his view, no reason at all-to believe in moral facts.

Officially, Harman's argument thus far is directed against belief in irreducible moral facts. He also expresses reservations about the possibility of offering a plausible and sufficiently detailed naturalistic reduction of moral facts. But it is clear from his presentation that his objections against belief in irreducible moral facts, as well has his reservations about the possibility of reducing moral facts to non- moral facts, apply equally to belief in objective moral properties and to the possibility of reducing such properties to non-moral ones. Thus, I will henceforth talk about Harman's argument and responses to it as if what is at issue is belief in objective moral properties rather than belief in moral facts. Also, unless otherwise indicated, I will use the term 'moral properties' unqualified as shorthand for the term 'objective moral properties'.

I have already mentioned two ways of replying to Harman's argument: defend $\mathrm{C} 1$ or defend C2. Before discussing those replies, however, I want first to identify and set aside two other ways of replying. As I understand it, Harman's argument rests on four premises:

(P1) Irreducible moral properties have no (indispensable) role to play in our best causal explanations of any natural phenomena.

\footnotetext{
${ }^{10}$ Note that ' $x$ because $y$ ' isn't equivalent to, and does not entail ' $x$ is a cause of $y$ '. We might say 'The vase broke because it was fragile'; but in saying this we don't commit ourselves to the claim that the fragility of the vase caused its breaking.
} 
(P2) Moral properties are not reducible to non-moral properties that play indispensable roles in our best causal explanations of natural phenomena.

(P3) Scientific justification proceeds by way of inference to the best (causal) explanation.

(P4) If there is no scientific justification for believing in $x \mathrm{~s}$, then there is no justification at all for believing in $x \mathrm{~s}$.

$\mathrm{C} 1$ and $\mathrm{C} 2$ are attacks on $\mathrm{P} 1$ and $\mathrm{P} 2$ respectively. But one might also resist the argument by attacking either P3 or P4. Attacking P4 is unacceptable from a naturalistic point of view, however-not because science couldn't provide reason for rejecting P4, but because (as far as we know) science hasn't offered reason to reject $\mathrm{P} 4 .{ }^{11}$ Thus, short of defending $\mathrm{C} 1$ or $\mathrm{C} 2$, the only other avenue of reply is to attack P3.

For the most part, $\mathrm{P} 3$ has gone unquestioned in the literature; ${ }^{12}$ and the importance of $\mathrm{C} 1$ in the moral realism debate is powerful testimony to the fact that naturalists, in general, have been prepared to accept it. P3 is not beyond question, of course. But I doubt that there are alternatives that stand a better chance of being compatible with both naturalism and realism about the entities posited in scientific theories. Bas van Fraassen (1989), for example, is a wellknown critic of inference to the best explanation, but his own conception of scientific justification is explicitly anti-realist. Likewise, Richard Boyd (1988) urges the conclusion (superficially contrary to what philosophers like Harman seem to think) that the method of reflective equilibrium is the method of science. But Boyd does not deny that the method of reflective equilibrium as he understands it is equivalent to what Harman would call "the inference to the best explanation", and a look at Harman's explicit account of inference to the

\footnotetext{
${ }^{11}$ Scientific reasons for rejecting $\mathrm{P} 4$ would just be scientific reasons for believing that there ae non-scientific sources of evidence (e.g., clairvoyance, rational intuition, etc.).
} 
best explanation bears out the equivalence. (Cf. Harman 1965) Moreover, Boyd (1982, 1988) concedes what will be crucial for my point later on-namely, that by employing the method of reflective equilibrium as a method of theory choice, we inevitably choose theories in part on the basis of simplicity considerations. ${ }^{13}$ This fact is all that I aim to establish by assuming with Harman that scientific justification proceeds by way of inference to the best explanation. ${ }^{14}$ But it is, I think, a fact that will be as easily established under any other plausible assumption (like Boyd's) about the process of scientific justification that purports to be compatible with scientific realism.

Granting P3 and P4, the only way to resist Harman's argument is to endorse either C1 or C2. As it happens, I think that both $\mathrm{C} 1$ and $\mathrm{C} 2$ are false; but in the remainder of this section my main concern will simply be to show that, even if one or the other is true, naturalistic arguments in support of moral realism must ultimately rest on an appeal to simplicity.

\subsection{Inference to the Best Explanation}

According to $\mathrm{C} 1$, objective moral properties play an indispensable role in the best causal explanations of at least some natural phenomena, and this regardless of whether they are reducible to non-moral properties. Plausible examples in support of $\mathrm{C} 1$ are hard to find; but three seem especially worthy of attention. First, one might note that we often regard the moral judgment of others as being more or less reliable than our own. But, one might think, one's moral judgment can be reliable only if the presence or absence of moral properties at least partly

\footnotetext{
${ }^{12}$ For the most part, but not entirely. See, e.g., Sayre-McCord 1988 b.

13 As I'll note in Section 3, Boyd understands the notion of simplicity in a way different from the way I am understanding it here. But I'll also argue that understanding simplicity in his way won't help a naturalist to avoid the conclusion that I am defending.

${ }^{14}$ I also assume that, so far as scientific justification is concerned, there is no distinction to be drawn between inference to the best explanation and inference to the best causal explanation. Hence, I'll drop the qualifier here and, for the most part, in what follows.
} 
causally explains one's moral beliefs. (Sturgeon 1986: 71-2; Adams 1999: 67-8) Second, one might note that we're inclined to believe that, say, moral depravity leads people to do terrible things, or that moral decency keeps people from doing such things. But this too might seem to make sense only if moral properties enter into causal explanations. (Sturgeon 1986: 74-5) Third, one might think that “certain regularities_-for instance, honesty's engendering trust or justice's commanding allegiance, or kindness's encouraging friendship — are real regularities that are unidentifiable and inexplicable except by appeal to moral properties." (Sayre-McCord 1988b: 276) Here too, then, we might seem to have a case of moral properties playing a role in causal explanations.

My own view is that naturalists should not put much stock in examples like these. Kurt Gödel's mathematical sensibilities were more reliable than my own; and both Fermat's Last Theorem and Goldbach's Conjecture have kept many a mathematician up late at night. Does it follow from any of this that mathematical propositions or properties enter into causal explanations? Ironically enough, Harman would probably concede that mathematical propositions and properties do enter into causal explanations, but that is only because they play an indispensable role in the sorts of causal explanations that constitute our best physical theories. It is emphatically not because they must be invoked as causes either of mathematical beliefs or of insomnia. As Harman points out, however, moral propositions do not enter into physical theory, or any other scientific theory, in the way that mathematical propositions do. And I think that there is no more reason to think that they must be (or even can be) invoked as causes of moral beliefs or morally significant behavior than there is to think that mathematical properties or propositions can be invoked as causes of mathematical beliefs or of insomnia. Of course, if Sayre-McCord is right in thinking that there are at least some regularities in the world that are 
"unidentifiable and inexplicable" apart from an appeal to moral properties, then there is reason to think that moral properties enter into our best causal explanations of natural phenomena. But I see no naturalistically acceptable reason for thinking that Sayre-McCord's claim is true. Consider his first example: honesty's engendering trust. The clear, empirically detectable regularity here is a connection between a certain kind of truth-telling disposition and various other dispositions to believe and act on the things that are said by people with the first disposition. But why think that this regularity can't be identified or explained apart from an appeal to moral properties? Similar remarks apply to the other examples on Sayre-McCord's list.

I needn't press this point, however. For, as I will now argue, there's good reason to think that, regardless of whether $\mathrm{C} 1$ is true, any scientific justification we might have for belief in objective moral properties will depend on an appeal to simplicity. As Section 3 will make clear, this is all that is required to show that naturalists cannot accommodate belief in objective moral properties.

Suppose, as we have been, that scientific justification proceeds by way of inference to the best explanation. There are, very roughly speaking, two ways in which we can be justified by an inference to the best explanation in believing that properties of a certain kind are exemplified. The properties in question might be among the explainers, explicitly posited as salient causes of particular empirical phenomena. Or their existence might be implied by background presuppositions which are part of the theory because of their simplifying role (i.e., their presence in the theory helps to make it more elegant, more ontologically economical, less mathematically complicated, or more consistent with our considered judgments, theoretical commitments, or other entrenched presuppositions). I do not mean to suggest that there is any sharp distinction to be drawn between explanatory posits and background assumptions. But there is at least an 
intuitive, rough-and-ready distinction here that is worth attending to. So, for example, if belief in the fundamental, causally efficacious properties of protons is justified by an inference to the best explanation, it is so because those properties are posited by our best explanations of various empirical phenomena as causes of those phenomena. On the other hand, if belief in the kindproperty being a proton is justified by an inference to the best explanation, it probably is so not because that property too is posited as a cause of various empirical phenomena, but rather because our theories are simplified by framing them in terms of an ontology that includes protons rather than, say, in terms of an ontology that includes only mere bundles of the more fundamental properties, or aggregates of instantaneous proton-stages, or something else empirically but not metaphysically equivalent. I say this because, plausibly, there is nothing that would be causally explained by the property being a proton that isn't already causally explained by the more fundamental, intrinsic, non-sortal properties of protons. Likewise, I think, with properties like being a material object, being an enduring particular, and being an intrinsic modal property. Such properties are either causally inert or causally redundant. Thus, whatever scientific justification we have for believing in them would seem to come from the simplifying role they play in our theories, since whatever causally explanatory roles they might be thought to play are either spurious or else already being played by other, more fundamental properties.

Now, it is hard to take seriously the idea that moral properties are explanatory posits. That is, it is hard to take seriously the thought that our main reason for believing in moral properties is that our best scientific theories posit them as the salient explanatory causes of particular empirical phenomena. As we have seen, some do claim that moral properties are causally efficacious and that they play a role in our best explanations of natural phenomena. But no naturalist seems seriously to think that the explanations in question invoke moral properties to 
explain phenomena that are otherwise causally unexplained. To whatever extent moral properties are causally efficacious at all, from a naturalistic point of view they are either reducible to nonmoral properties or else irreducible but causally redundant. In either case, all of the relevant explanatory work is already done by non-moral properties. Thus, there is no need to posit distinctively moral properties for explanatory purposes. So if belief in moral properties is justified by an inference to the best explanation, this must be because our theories are somehow simplified by framing them in terms of an ontology that includes moral properties rather in terms of one that doesn't.

Further evidence for this comes from the fact that none of the major defenders of the explanatory value of moral properties attempts to defend the claim that moral properties are explanatory posits. Nicholas Sturgeon $(1985,1986)$, for example, makes it his strategy to assume that there are moral properties and then to show that, on that assumption, such properties have a role to play in our explanations of various phenomena. Thus, rather than attempt to show that moral properties must be posited to explain various phenomena, he only aims to show that explanatory roles can be found for moral properties if we take for granted (presumably for other reasons) that there are such properties. Boyd (1988), Jackson (1998), Jackson \& Pettit (1995), Railton (1986), and Sayre-McCord (1988b) among others all take similar strategies. And this is precisely the strategy we should expect to find naturalistic proponents of $\mathrm{C} 1$ taking if, as I have argued, whatever scientific justification we have for belief in moral properties comes from the simplifying role of such belief.

There is another reason for thinking that if belief in moral properties is justified by an inference to the best explanation then it is justified in part on pragmatic grounds. It is widely believed that, in science, what counts as the best explanation of some phenomenon is determined 
in large part by what I have called simplicity considerations, broadly construed. ${ }^{15}$ I will not attempt to defend this view here; but if it is true, then it follows directly that, if belief in moral properties is justified by an inference to the best explanation, it's justification depends ultimately upon an appeal to simplicity.

\subsection{The Irrelevance of Reducibility}

According to $\mathrm{C} 2$, moral properties are reducible to non-moral properties that figure in our best causal explanations of natural phenomena. I take it that, in the context of the moral realism debate, the project of reducing moral properties to non-moral properties is just the rather broad project of trying to show how moral properties might be identical with or in some sense composed of properties that are quantified over in paradigmatically scientific theories. (Thus, there is no reason to suppose that a reduction would have to provide "bridge principles" explicitly identifying specific properties mentioned in existing moral theories with specific properties mentioned in existing physical, chemical, or biological theories.) In the remainder of this section, I will argue that even if objective moral properties are reducible to non-moral properties, naturalists still must appeal to simplicity in order to justify belief in such properties. If I am right, then establishing the reducibility of moral properties to non-moral properties is of no use to a naturalist hoping to resist the overall conclusion of this paper.

The basic problem is just this: Demonstrating reducibility is not the same as demonstrating the truth of a particular reduction. Plausibly, one can demonstrate reducibility simply by showing that if we take moral realism for granted, and if we take for granted various assumptions about what non-moral properties are objectively good or bad, or about what non-

15 Cf. Koons 2000, Lipton 1991, and Swinburne 2001 (Ch. 4). Koons 2000 argues that, because simplicity considerations play such an important role in scientific justification, naturalists cannot accommodate scientific 
moral states of affairs are objectively rational to promote or to avoid, then moral properties will be identical with or composed of the members of a certain class of non-moral properties. Demonstrating the truth of a particular reduction, however, requires one to demonstrate, in addition, the truth of moral realism and the correctness of one's various assumptions about what non-moral properties are objectively good or bad and about what non-moral states of affairs are objectively rational to promote or to avoid. Thus, even if we are presented with a perfectly compelling argument for the conclusion that objective moral properties are reducible to nonmoral properties, we are still left with the question of why we should believe that there are any objective moral properties. And here we are returned to the pair of options sketched in section 2.2: Assuming we are naturalists, we either posit moral properties as non-redundant causal explainers of natural phenomena (an option hardly worth taking seriously) or we presuppose their existence as a way of simplifying our theorizing.

To illustrate this problem, let me briefly sketch one well-known attempt to reduce moral properties to non-moral properties. In "Moral Realism” (Railton 1986), Peter Railton argues that facts about moral rightness are reducible to facts about what about what an impartial hypothetical observer would approve of under conditions of ideal information. These counterfactual facts, in turn, are supposed to be reducible to purely descriptive facts about the nature of the society in question, it's particular circumstances, and so on. As a first step into the task, Railton begins by showing how the non-moral good of an individual agent can be reduced to facts about what a cognitively idealized version of the agent would desire for his or her unidealized self. Crucial to his account is the idea of an agent's objectified subjective interest. Railton introduces that idea as follows:

realism. This is a conclusion that I am inclined to agree with, but adding to Koons's defense is not my purpose here. 
Give to an actual individual $A$ unqualified cognitive and imaginative powers, and full factual and nomological information about his physical and psychological constitution, capacities, circumstances, history, and so on. A will have become $A+$, who has complete and vivid knowledge of himself and his environment, and whose instrumental rationality is in no way defective. We now ask $A+$ to tell us not what he currently wants, but what he would want his non-idealized self $A$ to want-or, more generally, to seek-were he to find himself in the actual condition and circumstances of $A$.

What A+ would want A to want in A's actual condition and circumstances is what is in A's objectified subjective interest. By way of example, Railton invites us to consider a man who is dehydrated in the desert and finds himself desiring a glass of milk. In fact, a glass of water would be much better for the man from the point of view of improving his health; and, intuitively, it seems that a glass of water is what is objectively in his best interests (assuming, anyway, that he wants to survive and be healthy). Railton's account accommodates this intuition. On the assumption that the man desires to survive and be healthy, it turns out that drinking water is in the man's objectified subjective interest, since that is clearly what a cognitively idealized version of the man would desire his non-idealized self to desire in the man's actual condition and circumstances of dehydration. What is in a person's objective interest to do is just what he has an objectified subjective interest in doing; and the non-moral good for a person is to do what it is in his objective interest to do. Moreover, the fact that it is in a person A's objective interest to do something is supposed to supervene on "those facts about A and his circumstances that A+ would combine with his general knowledge in arriving at his views about what he would want to want were he to step into A's shoes." (174-5) Thus, Railton's view rightly yields the judgment that it is objectively non-morally good for the dehydrated man to drink water even though he 
actually wants to drink milk; and, plausibly, these facts about the man's non-moral good supervene on purely descriptive, non-normative facts. ${ }^{16}$

From here, the account of moral rightness unfolds roughly as follows. Moral rightness is understood as rationality from a social point of view; rationality is understood as the pursuit of what it is in one's objective interests to do; and so social rationality is understood as pursuit of whatever is in the objective interests of society. Furthermore, the objective interests of society are characterized in a way analogous to the characterization of the objective interests of an individual: again, roughly, those interests are whatever would be approved of by an impartial observer under conditions of ideal information. Of course, one's own objective interests might not coincide with society's; but, Railton says, facts about social rationality can still ground ought claims that apply to individuals because the social point of view "includes but is not exhausted by" the individual's. (1986: 201) Moreover, these ought claims will satisfy the two conditions I identified as necessary for objectivity since they are, in the relevant sense, theory-independent.

We may note in passing that, even if Railton's account thus far is true, it is not at all clear that it implies that moral facts are genuinely reducible to non-moral facts. ${ }^{17}$ The reason is that it is not clear what non-moral facts are supposed to determine the desire structure of the hypothetical observer; hence, it is not clear what facts determine the relevant hypothetical

\footnotetext{
${ }^{16}$ Railton's account of an agent's non-moral good is similar to the account of normative reasons offered in Smith 1994. Smith, however, does not take himself to be offering a fully reductive analysis of normative reasons. As he himself points out, normative concepts are employed in spelling out what it means for $\mathrm{S}$ to have a normative reason to $\varphi$. (162)

17 For the record, I do not believe that Railton's account thus far is true. The most compelling problem is that his account is unable to accommodate the fact that it might be in a person's objective interest to desire something but not to have it. Suppose it is a fact about Kevin that if he were to desire to go to medical school, he would embark upon a course of action that would very probably not result in his actually going to medical school but would result in his achieving something else that is very satisfying for himself (perhaps a career as a science teacher or some such thing). Suppose furthermore that if he were actually to go to medical school, he would be absolutely miserable. We may assume that Kevin himself does not know these facts, but that Kevin+ would know them. What then would Kevin+ desire to desire were he in the actual condition and circumstance of Kevin? Pretty obviously, he would desire to desire to go to medical school. But according to Railton's account, it does not follow from this that desiring
} 
reactions of approval and disapproval. In the case of an individual agent, Railton invites us to suppose that the desire structure of the agent's idealized self depends importantly upon the agent's actual desire structure. And we can see how the dependence would go: take that initial desire structure, and then suppose that it remains generally intact in the agent's idealized self except for whatever modifications would be induced by improving the agent's cognitive abilities and information base in the ways suggested. One might reasonably doubt that there are any facts about what modifications would be induced in an agent's desire structure by making the requisite cognitive improvements. ${ }^{18}$ But even if there are such facts, the point is that in the case of social rationality, a story analogous to this one about how the hypothetical observer's desire structure is to be determined seems impossible to tell. We might suppose that the hypothetical observer's desire structure would depend in some way upon the actual goals and desires of individual agents; but it is not at all clear how the dependence would go.

Let us leave this worry aside, however, and let us simply concede that Railton's account has shown us how moral facts might be reducible to non-moral facts. Still, Railton's account crucially depends on the assumption that one in some sense ought to act in accord with social rationality and that one ought to do what it is in one's objective interest (as defined by Railton) to do. Granted, we can see why, given a certain set of interests and desires, it would be attractive or efficient or useful to act in these ways, and that various tangible benefits would be produced by so acting. But Railton's reduction of non-moral goodness and moral rightness does not justify the claim that one objectively ought to pursue one's non-moral good and that one objectively ought

to go to medical school is in Kevin's objective interest, which is true; rather, it follows that going to medical school is in Kevin's objective interest, which is false.

18 As Mark Murphy (1999: 261-265) argues, there is also reas on to doubt (a) whether such modifications would all count as improvements in the agent's desire structure, and (b) whether there's any good reason to think that the hypothetical second-order desires of an agent's cognitively idealized self are any more authoritative with respect to the agent's well-being than the agent's actual second-order desires. 
to do what is morally right. As Railton himself points out, his defense of moral realism presupposes a particular understanding of morality and of rationality; and what he has shown is that if morality and rationality are to be understood in that way, then objective moral properties are reducible to non-moral properties. But what he has not shown (and has not purported to show) is that the methods of science do, or even could, reveal that morality and rationality are to be understood in the way that he understands them. In other words, Railton has shown, at best, that if there are objective moral properties, and if his assumptions about what non-moral states of affairs are objectively rational to pursue are correct, then objective moral facts are reducible to the sorts of facts he has described. He has not shown that his reduction is true.

One might think that we could go some distance toward showing that a particular reduction is true if we could show that the reduction in question has correctly identified nonmoral properties (or clusters of properties) that are tracked by our actual use of the terms 'morally good' and 'morally right'. ${ }^{19}$ But even if we could show this, we would still not have enough to show how belief in objective moral properties is justified. Consider the following two premises:

(1) If there are objective moral properties, and if theory $\mathrm{T}$ of the nature of morality, rationality, and related notions is correct, then moral properties are identical with or composed of natural properties $\mathrm{N}_{1}-\mathrm{N}_{\mathrm{n}}$. Our uses of words that allegedly refer to moral properties reliably track $\mathrm{N}_{1}-$ $\mathrm{N}_{\mathrm{n}}$.

${ }^{19}$ Boyd (1988) presses this point in his own attempt to show that moral properties are reducible to non-moral properties. 
Perhaps some interesting conclusions follow from these premises. But clearly the conclusion that there are objective moral properties does not follow from the premises. ${ }^{20}$ Thus, even if $\mathrm{C} 2$ is true, and even if it can be shown that a particular reduction has correctly identified natural properties tracked by our moral terms, there is still work for a naturalist to do in showing how belief in objective moral properties could be justified by the methods of science. And, for precisely the reasons laid out in section 2.2 , it seems that the only plausible stories to be told here are ones according to which belief in moral properties depends for its justification on considerations of theoretical simplicity.

\section{Pragmatic Arguments}

In Section 2, I argued that any naturalistically respectable argument for belief in objective moral properties will have to appeal to simplicity. In this section, I'll argue that appeals to simplicity justify belief in moral properties only if moral properties are not objective or something like theism is true.

Some philosophers make a distinction between pragmatic and epistemic justification. The distinction between the two parallels the distinction between pragmatic and epistemic rationality-i.e., the distinction between what is rational to do given the goal of furthering one's overall best interests and what is rational to believe in light of one's evidence given the goal of believing in accord with the truth. It is epistemic justification that we're interested in here. And the initially pressing question is whether an argument that invokes considerations of simplicity as reasons for belief can provide epistemic justification for its conclusion.

For reasons I won't get into here, I'm inclined to think that one is automatically epistemically justified in believing things that are sanctioned by sources of evidence that one

\footnotetext{
${ }^{20}$ A somewhat related point is made by Robert Adams (1999: 77-8).
} 
treats as basic. ${ }^{21}$ Insofar as naturalists treat the methods of science as basic sources of evidence, and insofar as simplicity considerations are (apparently, anyway) routinely invoked as reasons for belief in the natural sciences, I am prepared to assume for the sake of argument that naturalists are epistemically justified in believing propositions that are supported by appeals to simplicity (especially those that figure in inferences to the best explanation or the method of reflective equilibrium). If this assumption is false, then my ultimate conclusion follows directly: naturalists are not epistemically justified in believing propositions supported (only) by arguments that appeal to simplicity; from a naturalistic point of view, belief in objective moral properties is sanctioned (if at all) only by arguments that appeal to simplicity; therefore, naturalists cannot reasonably accept commonsense moral realism. ${ }^{22}$ Thus, the initially pressing question—whether one can be epistemically justified in believing something partly on the basis of an appeal to simplicity—is resolved by stipulation.

But once the stipulation is granted, we are committed to thinking that there is some connection between simplicity and truth. The reason is that arguments appealing to simplicity can yield epistemic justification only if believing propositions on the basis of such arguments is a reliable way of believing in accord with the truth. ${ }^{23}$ Let us suppose, then, that simplicity is somehow a reliable indicator of truth. The pressing question now is: What would be the best explanation for this fact?

One interesting suggestion that I'll set aside is that our preference for simplicity is just a disguised preference for truth. According to Richard Boyd (1980, 1985), for example, what often get described as considerations of simplicity are really nothing more than manifestations of a

\footnotetext{
${ }^{21}$ I defend this claim in Chapter 1 of Rea 2002.

${ }^{22}$ I assume that one can reasonably accept only what one is epistemically justified in believing. But this is just a terminological point — a point about how I am here proposing to use the word 'reasonably'.

${ }^{23}$ Or so I assume. But I acknowledge that the assumption is controversial.
} 
preference for theories that are relatively "simple" modifications of existing, evidentially supported theories. Thus, given that our existing theories are at least approximately true, the preference for simplicity turns out, on this view, to be little more than a preference for (approximate) truth.

There is a lot that is worth exploring in this view, but for now I'll simply observe that adopting it leaves the naturalist no better off with respect to belief in objective moral properties than I have so far taken her to be. Suppose we grant that "existing moral theory" (whatever exactly that would be) is approximately true. The fact is, this might be so whether or not there are objective moral properties, and whether or not existing moral theory quantifies over objective moral properties. Now, if Boyd's understanding of simplicity is correct, then one who believes in objective moral properties on the basis of such considerations believes in them either because so doing represents a simple modification of an existing theory, or because their existence is already implied by an existing theory. In light of the arguments of Section 2, it is hard to see what reason a naturalist could ever have for modifying an existing theory so that it quantifies over objective moral properties. An appeal to simplicity is ruled out because, on Boyd's view, that's not a reason for modifying a theory; it's a reason for preferring one modification rather than another. But the point of Section 2 was to show that, from a naturalistic point of view, there aren't any (evidential) considerations apart from simplicity that would lead one to posit objective moral properties. Thus, if Boyd's understanding of simplicity is right, then if existing moral theory quantifies over objective moral properties, it does so for no reason at all, or it does so simply because existing moral theory has always quantified over such properties. Thus, if his view is right, it looks as if a naturalist's belief in objective moral properties is either ungrounded or grounded simply in the fact that such belief is and always has been prescribed by existing moral 
theories. But even if we grant that believing something simply because you (or others) always have believed it is a reliable way of reaching the truth, nothing in Boyd's view explains why this should be a reliable way of reaching the truth. It's easy to see how a preference for existing theories can reliably lead us to approximate truth, given that those existing theories are already approximately true. But it doesn't help us to see how a preference for existing theories in general can lead us to the truth about specific parts of a theory-such as the proposition that there are objective moral properties. Thus, it remains a mystery how believing a specific proposition simply because you and others have always believed it should be a reliable way of reaching the truth. And I take it that the answers to this question will roughly parallel the answers to the more general question at issue here-namely, the question of what would explain the fact that simplicity considerations as I understand them are generally truth-indicative.

So what would explain the fact that simplicity is truth-indicative? One possibility is that someone or something in the universe is somehow benevolently guaranteeing that it will be. This, clearly enough, is in the neighborhood of theism. Another possibility is that a pragmatic theory of truth is correct: truth is, roughly, acceptability or assertibility under ideal conditions, where "ideal conditions" are spelled out partly in terms of simplicity considerations. A third possibility, constructivism, is that we make it the case that our theories are true by conceptualizing the world in whatever way we do. ${ }^{24}$ Thus, so long as we conceptualize the world in a way that is empirically adequate (as our scientific theories aim to do) there is no real question whether the ontological commitments we thereby incur will be true. ${ }^{25}$ On this view,

\footnotetext{
${ }^{24}$ Here I am not using the term 'constructivism' in the way that Rawls (1980) does. Rather, the view I have in mind is primarily a view about ontology, and it often goes by labels like conventionalism, (global) anti-realism, Kantian idealism, and so on (though somewhat different views go by those labels too).

${ }^{25}$ It is, perhaps, tempting to conflate the third possibility with the second. But we can avoid the temptation if we attend to the fact that constructivism, insofar as it is coherent, is compatible with deflationism about truth-a rejection of more substantive theories of truth in favor of the view that Tarksi's T-schema says all there is to say
} 
simplicity isn't really an indicator of truth (truth is guaranteed by empirical adequacy); rather, it is just a constraint that happen to govern our theorizing.

It is hard to imagine (plausible) explanations other than these for why simplicity would be a reliable indicator of truth. ${ }^{26}$ Of course, one can't infer much from a mere failure of imagination. But if, upon reflection, we simply can't see why theoretical virtues that we take to be truth-indicative should be truth-indicative, it is hard to see how we can be justified in continuing to treat them as truth-indicative. Thus, assuming it is non-negotiable for naturalists to continue treating simplicity as a reliable indicator of truth, and assuming that they (like me) have no other plausible story to tell about why it ought to be a reliable indicator of truth, it seems that the only reasonable option is to embrace one of the above three alternatives. As a theist, I am sympathetic to the first. Moreover, the second (as I shall argue) implies something very much like theism. Thus, on the assumption that the methods of science do not by themselves justify belief in God, or even something very much like God, naturalists are committed to the third alternative. In what follows, I'll first explain why accepting constructivism commits one to the conclusion that moral properties are not objective. I'll then go on to argue that pragmatic theories of truth imply something very much like theism.

To see why constructivism requires us to give up the objectivity of moral properties, we must first get a clearer grasp on what the position amounts to. At first blush, it might seem to be incoherent. It is, after all, rather hard to see how we could accomplish the creative feats that

\footnotetext{
about truth. For more on constructivism, see Chapter 1 of Rea 2002. For detailed arguments for the conclusion that constructivism does not imply a pragmatic theory of truth, see Alston 1996, Ch. 6.

${ }^{26}$ Koons (2000) discusses a suggestion by David Papineau and Ruth Millikan to the effect that perhaps evolutionary processes have "taught" us that there is a correlation between (e.g.) simplicity and truth. Weinberg (1994) makes a similar suggestion. But, as Koons points out, accidental correlation isn't sufficient for reliable indication. The laws might have been complex; indeed, for all we presently know, the actual laws might (unexpectedly) in fact be complex. After all, we don't yet have the much sought after "final theory". So even if the Papineau-MillikanWeinberg suggestion is true, it remains hard to see what would give us grounds for thinking that virtues like simplicity are reliable indicators of truth.
} 
constructivism seems to require. How could we make it the case that there are stars, or planets, or human organisms simply by theorizing about the world in a way that quantifies over stars, planets, and human organisms? More pressingly, how could we-by using our minds—make it the case that there are minds? These are serious questions; but I think that constructivists can provide answers, and a brief look at those answers will help to clarify the position as I understand it.

The second question can be treated quickly. As I see it, constructivists must simply deny that we make it the case that there are minds; thus, they must deny that minds are part of the material world that is constructed by our theories. ${ }^{27}$ If this is right, then constructivists are committed to substance dualism. This is surely an interesting (and probably generally unwelcome) consequence; but it is not a refutation, and embracing it enables the constructivist to avoid the charge of incoherence.

The first question is more complicated. In response to it, I think that constructivists should articulate what many take to be a Kantian view of the world. Roughly, that view is as follows. None of the properties that appear to be sortal properties of non-abstract, non-mental objects are intrinsic to anything. Properties like being an electron, being a horse, being a star, being a human organism, and so on are all extrinsic. Notoriously, it is hard to say exactly how such properties could be extrinsic. The most intelligible versions of constructivism typically make it clear that the reason they are extrinsic is that whether they are exemplified depends importantly upon relations obtaining between our minds and the mind-independent world (i.e., whatever thing or things of a wholly unidentifiable sort exist independently of our minds). ${ }^{28}$

\footnotetext{
${ }^{27}$ I defend this conclusion in detail in Chapter 7 of Rea 2002.

${ }^{28}$ The thing or things belonging to the world $x$ it is in itself must be of an unidentifiable sort because the constructivist's thesis is that all of the sortal properties we are familiar with are extrinsic; but if the thing(s)
} 
Moreover, they make it clear that those relations involve, at least in part, our conceiving of the world in the ways that we do. But beyond this, it is hard to say exactly what the relevant relations consist in.

Be that as it may, some analogies may help to clarify the position a bit further. Consider some other properties that are often, even if not universally, regarded as "being in the eye of the beholder": properties like being a work of art, or being a thing of great beauty. The constructivist might say that, just as the matter in a region of spacetime counts as a work of art or a thing of great beauty only if we (or the members of some relevant group) think of it as a work of art or a thing of great beauty, so too whether the matter in a region of spacetime counts as a star, or a planet, or a human organism, depends upon our thinking of it as a star, or planet, or human organism. Likewise, she might say, just as there would be no art, or nothing beautiful, if we regarded nothing as art or as beautiful, so too there would be no stars if we regarded nothing as a star. There would, of course, still be the stuff that causes our star-like sensations. That stuff is part of the mind-independent world. ${ }^{29}$ But apart from our belief-forming activities, that stuff would not constitute a star.

Even with these analogies on hand, we are still a far cry from having answered all of the questions one might have about the intelligibility of constructivism. But we at least have enough of a picture to see clearly why moral constructivism is incompatible with commonsense moral realism. Quite simply, constructivism implies that goodness, like beauty or art, is in the eye of the beholder. Admittedly, matters will probably be a bit more complicated than this. Constructivism is, for example, compatible with the view that what's good is what the members

belonging to the world in itself is (are) to be truly mind-independent, it (they) must have its (their) sortal properties intrinsically. 
of some salient majority take to be good, or what our most pragmatically virtuous theories identify as good. But regardless of the details, any constructivist theory will, by its very nature, make facts about goodness dependent upon our beliefs about goodness. Thus, a constructivist account of goodness will not be an account according to which goodness is a theory-independent property; hence, it will not be an account according to which goodness is an objective property; hence, it will be incompatible with commonsense moral realism.

All that remains, then, is to deliver on my claim that pragmatic theories of truth imply something like theism. I have defended this conclusion at length elsewhere (Rea 2000, Rea 2002), so for present purposes I will only provide a brief sketch.

My argument draws its inspiration from Alvin Plantinga's 1982 Presidential Address to the American Philosophical Association. In that address, Plantinga argues that a thesis about truth which he attributes to Hilary Putnam implies that, necessarily, there exists an ideally rational community. The Putnamian thesis about truth is as follows:

(HP) Necessarily: $p$ is true $\equiv$ if there were an Ideally Rational Scientific Community (IRS) that had all of the relevant evidence, it would accept $p$.

In short, Plantinga points out that, by substitution, we can easily obtain HP1:

(HP1) Necessarily: it is true that there is an IRS $\equiv$ if there were an IRS that had all of the relevant evidence, it would accept that there is an IRS.

But, of course, it is eminently plausible that an IRS possessed of "all the relevant evidence" would accept the conclusion that there is an IRS. Thus, HP1 implies the "dismal conclusion" that, necessarily, there exists an IRS.

\footnotetext{
${ }^{29}$ Note that 'stuff' is not being treated here as a sortal term. There is, in other words, no object kind (or even a particular stuff-kind) that is referred to by the word 'stuff'. (If there are stuff-kinds, then stuff is just whatever it is that stuff-sortal terms sort.)
} 
HP is what we might call an epistemic truth equivalence (or "ETE" for short). An ETE is any claim that asserts that there is a necessary equivalence between what is true and what would be believed by a rational agent or community of agents under certain specified conditions. More exactly, an ETE is any thesis that conforms to the following schema:

(E) Necessarily: $p$ is true $\equiv$ if there were a rational community that satisfied condition $\mathrm{C}$ with respect to $p$, then there would be a rational community that both satisfies condition $\mathrm{C}$ with respect to $p$ and accepts $p$.

By 'rational community', I just mean 'a being or group of beings capable of thought and reasoning'. 'Condition C' refers to what we might call "the acceptance condition". It is a schematic term that takes as substitution instances descriptions of the conditions that must be satisfied by a rational community in order for its acceptance of $p$ to be necessary and sufficient for the truth of $p$. The "with respect to $p$ " qualifier is added to take account of the fact that what counts as satisfying the acceptance condition might vary from proposition to proposition. Such would be the case if, for example, the acceptance condition is satisfied only if the community in question possesses all and only the evidence relevant to $p$.

The first premise in my argument for the conclusion that pragmatic theories of truth imply something like theism is that pragmatic theories of truth entail epistemic truth equivalences. Below are some representative examples of claims that might be taken to express pragmatic theories of truth:

"True ideas are those that we can validate, corroborate, and verify" (James 1907:

"The opinion which is fated to be ultimately agreed to by all who investigate, is what we mean by the truth..." (Peirce 1878: 139) 
"[T]ruth is an idealization of rational acceptability. We speak as if there were such things as epistemically ideal conditions, and we call a statement 'true' if it would be justified under such conditions." (Putnam 1981: 55)

Truth is superassertibility, or "assertibility which would be durable under any possible improvement to one's state of information". (Wright 1992: 75)

Pretty obviously, each of these claims taken as a theory of truth is equivalent to a thesis that satisfies schema (E). Granted, one might argue (quite convincingly in some cases) that these authors did not really mean to be giving a theory about what truth is. But each of these views is such that if it were a theory of truth, it would clearly be a pragmatic theory and it would clearly imply an ETE. Moreover, I see no way in which a theory of truth could plausibly count as pragmatic without implying an ETE; for what makes a theory of truth distinctively pragmatic is just its having as a consequence the claim that truth is importantly tied to what is useful (in some sense) for humans to believe.

Of course, there are theses that imply that truth is importantly tied to what is useful for humans to believe but that do not imply ETE's. For example:

(W) Were P to be appraised under (constructively specified) sufficiently good epistemic conditions, $\mathrm{P}$ would be true if and only if $\mathrm{P}$ would be believed.

(Wright 2000: 350)

As Crispin Wright points out, conditionals like W serve to constrain the notion of truth in the ways that pragmatists typically want; and, importantly, they do not suffer from many of the problems that plague ordinary ETE's. But, though W-style conditionals surely say something interesting and important about truth, they are not theories of truth. A genuine theory of truth will offer or imply, at the very least, a necessary equivalence of the form 'Necessarily, $p$ is true $\equiv$ 
. And, again, it is hard to see how any such equivalence could constitute a pragmatic theory of truth without being or entailing an ETE.

The second premise in the argument is that every ETE implies something like theism. To establish this conclusion, I need two assumptions. The first is that it is possible that there are no contingent beings. The second is as follows:

(SC) For any true ETE: Let $\mathrm{C}$ be its acceptance condition and let $\alpha$ be the following proposition:

$(\alpha)$ There exists a rational community $\mathrm{S}$ such that, for every proposition $p, \mathrm{~S}$ satisfies $\mathrm{C}$ for either $p$ or the denial of $p$.

Then: Necessarily, if there is a rational community that satisfies $\mathrm{C}$ with respect to $\alpha$, then $\alpha$ is true.

The first assumption isn't wholly uncontroversial; but I assume it will be granted by most naturalists. After all, naturalism typically (though not necessarily) goes hand-in-hand with atheism, and atheists are typically prepared to admit that there might have been nothing at all. Regarding SC, the idea is roughly just that only a being ideally situated with respect to every proposition would be in an ideal position to evaluate a proposition like $\alpha$. A less-than-ideally situated being (e.g., a being very much like one of us) might have less-than-ideal evidence for either $\alpha$ or its denial. But having ideal evidence in favor of $\alpha$ would guarantee it's truth (since ideal evidence must be infallible), and having ideal evidence against $\alpha$ seems to be impossible (since, plausibly, only a being ideally situated with respect to every proposition could infallibly rule out the truth of something like $\alpha$ ). 
Given these two assumptions, the second premise can be defended as follows. Let EC below be any true ETE (if such there be); let C be EC's acceptance condition; let $\alpha, \beta$, and $\gamma$ be propositions as follows:

$(\alpha)$ There exists a rational community $\mathrm{S}$ such that, for every proposition $p, \mathrm{~S}$ satisfies C with respect to either $p$ or its denial.

( $\beta$ ) There exists a rational community that satisfies $C$ with respect to $\alpha$.

( $\gamma$ ) There exists a rational community that both satisfies $\mathrm{C}$ with respect to $\alpha$ and accepts $\alpha$.

We then have:

(EC) Necessarily: $p$ is true $\equiv$ if there were a rational community that satisfied condition $\mathrm{C}$ with respect to $p$, then there would be a rational community that both satisfies condition $\mathrm{C}$ with respect to $p$ and accepts $p$. (Premise)

(6.1) Necessarily: $\alpha$ is true $\equiv$ if $\beta$ were the case then $\gamma$ would be the case. (From EC, by substitution)

(6.2) $\quad \beta \Rightarrow \alpha($ From SC)

(6.3) Necessarily: $\alpha$. (From 6.1, 6.2)

6.1 and 6.2 together entail 6.3 on the assumption that the correct modal system is $\mathbf{S 4}$ or stronger and that the correct semantics for counterfactuals guarantees that (i) a counterfactual conditional implies its corresponding material conditional, and (ii) a strict conditional implies its corresponding counterfactual conditional. ${ }^{30}$ But from 6.3, it is a short step to the conclusion that, necessarily, there exists an omniscient community. 6.3 implies that it is necessarily true that there exists a rational community $\mathbf{S}$ such that, for every proposition $p, \mathrm{~S}$ satisfies $\mathrm{C}$ with respect 
to either $p$ or its denial. But this in conjunction with EC implies that it is necessarily true that, for every true proposition $p^{*}$, there is a rational community that both satisfies $\mathrm{C}$ with respect to $p^{*}$ and accepts $p^{*}$. Hence, it follows that, necessarily, there is a rational community that accepts a proposition that tells the whole truth about whatever world is actual. ${ }^{31}$ Thus, necessarily, there exists an omniscient community. Moreover, if one is willing to grant that the correct modal system is $\mathbf{S 5}$, then 6.3 implies that there exists a necessarily existing rational community. Again, 6.3 implies that it is necessarily true that there exists a rational community; but, on the assumption that it is possible that there be no contingently existing beings, it follows that there is a possible world $w$ that contains a rational community but no contingently existing rational beings. Thus, $w$ must contain a necessarily existing rational community. But this implies that there in fact exists a necessarily existing rational community. ${ }^{32}$

If this argument is sound, then pragmatic theories of truth entail that (a) necessarily there exists an omniscient community, and (b) there exists a necessarily existing rational community. This isn't quite theism, but it is close. Theists, of course, will not be bothered by this conclusion, for their view already entails it and (typically) is motivated by considerations independent of a commitment to an epistemic account of truth. Naturalists, on the other hand, ought simply to reject epistemic accounts of truth; hence, they ought also to reject pragmatic theories of truth. However, as we have already seen, naturalists who reject a pragmatic theory of truth must either embrace theism or give up belief in objective moral properties. Assuming, as I have been, that belief in God is not justified by the methods of science, the first alternative is unavailable (short

\footnotetext{
${ }^{30}$ For proof, see Rea 2000: 296 or Rea 2002: 152.

${ }^{31}$ Or, if there is no such proposition, then at least this much follows: necessarily, for any true proposition that approximates telling the whole truth about the world, there is a rational community that accepts it.

${ }^{32}$ Here are the steps: Let $\mathrm{W}$ be a world with no contingently existing rational beings and let $\mathrm{E}_{1}-\mathrm{E}_{\mathrm{n}}$ be the members of the rational community that exists in $\mathrm{W}$. We then have:

(1) $\diamond \square \mathrm{P} \Rightarrow \square \mathrm{P}$ [provable in the $\mathbf{S 5}$ modal system]
} 
of giving up naturalism). Thus, we reach the main conclusion of this paper: naturalists must give up moral realism.

(2) $\diamond \square\left(\mathrm{E}_{1}-\mathrm{E}_{\mathrm{n}}\right.$ exist.)

(2) Therefore: $\square\left(E_{1}-E_{n}\right.$ exist.) 


\section{REFERENCES}

Adams, Robert (1999), Finite and Infinite Goods (New York: Oxford University Press)

Alston, William (1996), A Realist Conception of Truth (Ithaca, NY: Cornell University Press.)

Armstrong, David (1980), "Naturalism, Materialism, and First Philosophy," reprinted in Paul Moser and J. D. Trout (eds.), Contemporary Materialism (New York: Routledge, 2002), $35-46$.

Boyd, Richard (1988), "How to be a Moral Realist,” in Sayre-McCord (1988: 181-228). (1985), "Observation Explanatory Power, and Simplicity," in P. Achinstein and O.

Hannaway (eds.), Observation, Experiment, and Hypothesis in Modern Physical Science (Cambridge, MA: MIT Press), 47 - 94.

_ (1981), "Scientific Realism and Naturalistic Epistemology," in Peter Asquith and Ronald Giere (eds.), PSA 1980, vol 2. (East Lansing, MI: Philosophy of Science Association), $613-662$.

Brink, David (1989), Moral Realism and the Foundations of Ethics (Cambridge: Cambridge University Press).

Copp, David and David Zimmerman (eds.), (1985), Morality, Reason, and Truth (Totowa, NJ: Rowman \& Allanheld).

Craig, William Lane and J. P. Moreland (eds.) (2000), Naturalism: A Critical Approach, (London: Routledge).

Danto, Arthur (1967), "Naturalism," in Paul Edwards (ed.), The Encyclopedia of Philosophy, vol. v (New York: MacMillan and Free Press), 448 - 50.

Devitt, Michael (1998), "Naturalism and the A Priori," Philosophical Studies 92: 45 - 65.

Hampton, Jean (1998), The Authority of Reason (Cambridge: Cambridge University Press). 
Harman, Gilbert (1977), The Nature of Morality, (New York: Oxford University Press).

_ (1984), “Is There a Single True Morality?” in Copp and Zimmerman (1985: 27 - 48).

(1986), "Moral Explanations of Natural Facts-Can Moral Claims Be Tested Against

Moral Reality?" Southern Journal of Philosophy 24 (supp.): 57 - 68.

Jackson, Frank (1988) From Metaphysics to Ethics (Oxford: Oxford University Press)

and Philip Pettit (1995), "Moral Functionalism and Moral Motivation," Philosophical

Quarterly 45: $20-40$.

Katz, Jerrold (1998), Realistic Rationalism (New York: MIT Press).

Koons, Robert (2000), “The Incompatibility of Naturalism and Scientific Realism,” in Craig \& Moreland (2000: $49-63)$.

Leiter, Brian (1998), "Naturalism and Naturalized Jurisprudence," in Brian Bix (ed.), Analyzing Law: New Essays in Legal Theory (Oxford: Clarendon Press), 79 - 104.

Lipton, Peter (1991), Inference to the Best Explanation (London: Routledge)

Murphy, Mark (1999), “The Simple Desire-Fulfillment Theory” Noûs 33: 247-72.

Plantinga, Alvin (1982), "How to be an Anti-Realist," Proceedings and Addresses of the American Philosophical Association, September 1982.

Quine, W. V. (1995), “Naturalism; or, Living within One's Means,” Dialectica 49: 251 - 62.

Railton, Peter (1986), “Moral Realism,” Philosophical Review 95: 163-207.

Rawls, John (1980), “Kantian Constructivism in Moral Theory,” Journal of Philosophy 77: 515 72.

Rea, Michael (1998), “Naturalism and Material Objects," in Craig \& Moreland (2000: 110 - 32) (2000), “Theism and Epistemic Truth Equivalences,” Nô̂s 34: 291 - 301. 
_ (2002), World Without Design: The Ontological Consequences of Naturalism (Oxford: Clarendon Press).

Sayre-McCord, Geoffrey (ed.) (1988a), Essays on Moral Realism (Ithaca, NY: Cornell University Press).

__. (1988b) "Moral Theory and Explanatory Impotence," in Sayre-McCord 1988a, 256-81.

Schmitt, Frederick (1995), "Naturalism," in Jaegwon Kim and Ernest Sosa (eds.), Companion to Metaphysics (Oxford: Basil Blackwell), 343 - 5.

Sellars, Wilfrid (1963), "Empiricism and the Philosophy of Mind," in Science, Perception, and Reality (London: Routledge \& Kegan Paul, 1963), 127 - 96.

Smith, Michael (1994), The Moral Problem (Oxford: Basil Blackwell)

Sturgeon, Nicholas (1985), “Moral Explanations,” in Copp \& Zimmerman (1985: 49 - 78).

_ (1986), "Harman on Moral Explanations of Natural Facts," Southern Journal of Philosophy 24 (supp.): $69-78$.

Swinburne, Richard (2001), Epistemic Justification (Oxford: Oxford University Press)

Van Fraassen, Bas (1989), Laws and Symmetry (Oxford: Clarendon Press)

Weinberg, Steven (1992), Dreams of a Final Theory (New York: Vintage Books) 